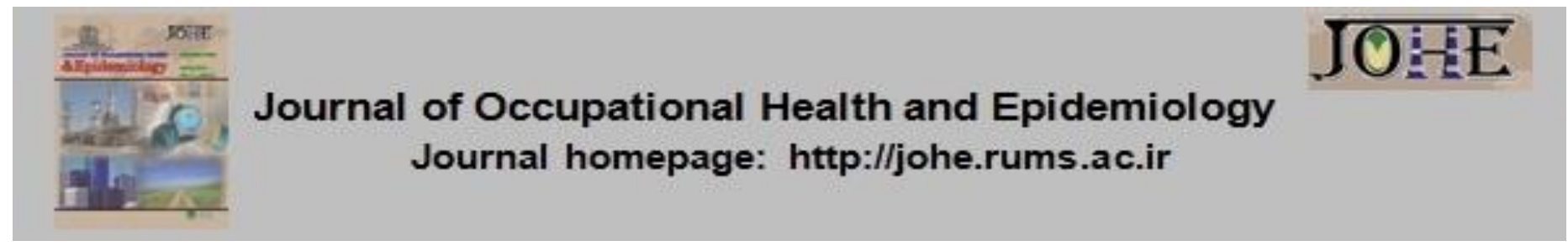

\title{
Risk assessment and identification of accident points at a highway construction site and drawing Safety Contour Maps (Southeastern Iran, 2019)
}

\author{
Hossein ElahiShirvan ${ }^{1}$, Sajad Zare ${ }^{2}$, Edris Gharanjik ${ }^{3}$, Arezoo Matin ${ }^{1}$, Mokhles Bateni ${ }^{1}$, Davood \\ Hasanvand ${ }^{1}$, Mohammad Reza Ghotbi Ravandi ${ }^{*}$ \\ 1- MSc in Occupational Health, Students' Research Committee, Kerman University of Medical Sciences, Kerman, Iran \\ 2- Assistant Prof., Department of Occupational Health, School of Public Health, Kerman University of Medical Sciences, Kerman, Iran. \\ 3- BSc in Occupational Health, School of Public Health, North Khorasan University of Medical Sciences, North Khorasan, Iran. \\ 4- Associate Prof., Department of Occupational Health, Students' Research Committee, Kerman University of Medical Sciences, \\ Kerman, Iran.
}

\section{Article Info}

* Corresponding author:

Mohammad Reza

Ghotbi Ravandi,

E-mail:

ghotbi@kmu.ac.ir

\section{Article history}

Received: Jul, 2019

Accepted: Aug, 2019

10.29252/johe.8.3.148

Print ISSN: 2251-8096 Online ISSN: 2252-0902

Peer review under responsibility of Journal of Occupational Health and Epidemiology
Citation: ElahiShirvan H, Zare S, Gharanjik E, Matin A, Bateni M, Hasanvand D, Ghotbi Ravandi MR. Risk assessment and identification of accident points at a highway construction site and drawing Safety Contour Maps (Southeastern Iran, 2019).JOHE 2019; 8(3):148-55.

\section{Introduction}

The occupational safety literature provides different theories about the recurrence of occupational accidents, which result in significant costs for companies, workers, and the society. Past research shows that there are more individuals with repetitive injuries associated with stress and gender than expected by chance alone. Research reports indicate that the majority of accidents occur at the workplace $(1,2)$. Safety management decisions must be made for selecting and prioritizing problem areas as well as safety system weaknesses based on the recognition of hazards encountered in each activity of the process so as to reduce occupational accidents. Research reports 337 million occupational accidents per year $(3,4)$.

Occupational accidents are among the major public health problems, which annually threaten the lives of many people in developing and developed countries and are also responsible for a 
high rate of inabilities and absenteeism; thus, occupational incidents play a critical role in the global financial burden of diseases (5). Both occupational accidents and injuries are caused by the risk factors that can be removed by performing measurements and following procedures. It should be noted that most industrialized countries possess a comprehensive occupational safety and health management system, which causes a significant reduction in occupational accidents (6).

Recent psychological studies in the field of incidents and their causes are associated with the factors of age, level of experience, and occupational characteristics of employees, from management's point of view (7). Hayes believes that in the occurrence of accidents, insecure behaviors (88\%), unsafe conditions (10\%), and unforeseen factors (2\%) are involved. By identifying the role of individuals' unsafe acts from the second half of the 20thcentury in developed countries, incident control programs were focused on people's unsafe behaviors (8). Studies on unsafe behaviors have shown that occupational stressors contribute greatly to insecure acts by employers through reduced focus, mental distraction, memory impairment, job delays, and reduced decision-making power (9). Job stressors along with adverse psychological effects can lead to the occurrence of occupational incidents, because of injuries to people and damage to equipment at the workplace (10). The role of communication with the safety department has also been studied. According to past research, the relationship between managers and the workforce has an important role in increasing employee safety and health, based on which the quality of the working relationships affects the incidence of unsafe behaviors and occupational accidents (11). Incident surveys in most countries show that the incident dispersion rate is not uniform in people at risk, and that $75 \%$ of incidents occur to $25 \%$ of people at risk under equal conditions; thus, human factor can be considered as the most effective factor in the occurrence of occupational incidents $(12,13)$. Although mortalities from occupational accidents have dropped significantly, the annual US Occupational Accident Report issues a record of 12,500 deaths and 2,200,000 disabling injuries per year (7). It is predicted that about 120 million job incidents and more than 200,000 deaths will occur annually due to job-related activities in the world $(14,15)$.

In fact, data are very valuable for making decision on risks, thereby improving the environment, facilities, and hazardous conditions, planning for emergencies, determining the level of acceptable risks, relevant policies, inspection, and the maintenance of industrial installations, as well as other items (16). There are several methods, such as ET \& BA, FTA, and SSHAfor identifying and assessing workplace hazards, among which Failure Modes and Effects Analysis (FMEA) is one of the valid techniques for identifying and assessing risks.

NASA first applied Failure Modes and Effects Analysis (FMEA) in 1963. This approach ultimately led to the automotive industry, which serves to identify and quantify potential defects in the design phase of products (17). FMEA has recently been used as a tool by automotive, aerospace, and electronics industries to identify, prioritize, and eliminate failure states, potential system problems, and pitfalls in the design phase and before releasing products to the market (18). Many industry-specific FMEA standards, such as those developed by the Association of Automobile Engineers, the Department of Defense, and the Automotive Industries Group, use the RPN number to measure the risk and severity of failures (19). FMEA usually examines the state-of-failure effects on a system's reliability, and this limits the use of FMEA significantly. Pickard et al proposed a method for integrating multiple failure modes into a single unit, which allowed for the system to be analyzed under multiple failure scenarios at one time (20).

Road construction projects are among the major and strategic projects, and a lot of them are implemented in Iran. This research is conducted aimed at investigating risks, risk assessment methods, as well as the importance of financial costs and personnel damage caused by workrelated accidents at a highway construction site in the southeast Iran using FMEA and by drawing safety contour maps by ArcGIS. Many studies have been done using FMEA, but no study has so far shown the range of safe points on the site map; however, this study considered the mentioned issue. Using the results of this research and through employing appropriate programs based on the root causes of accidents, the costs of accidents imposed directly or indirectly on the industries of Iran could be minimized.

\section{Materials and Methods}

This study was conducted to identify hazards and risk assessment methods at a highway construction site in the southeastern Iran using FMEA and by drawing safety contour maps with the help of ArcGIS in 2019. The mentioned site has an area of 10,000 square meters with 100 employees. This cross-sectional analytical study was conducted in 9 general steps, including 1 . 
Reviewing demographic data, 2. Identifying human risks, 3. Identifying risk causes, 4. Identifying risk effects, 5. Determining the severity and occurrence of risks, 6. Rating risks, 7. Controlling risks, 8. Entering the coordinates and RPNs of occupations for each location in ArcGIS, and 9. Drawing safety contour maps using ArcGIS $10.2(21,22)$.

Employees included in this study were working in the capacity and in the fields of sales, administrative-financial affairs, safety and health, water supply plants, asphalting, kitchens, flagging, logistics, facilities, repairs, welding, cutting, guarding, the technical department, crushing, asphalt rollers, soil rollers, finishers, asphalt plants, dumpers, water tankers, controllers, graders, loaders, light car drivers, implementers, managers, surveyors, and labs. Table 1 illustrates the overall worksheet of FMEA.

Table 1: Example of the FMEA worksheet

\begin{tabular}{|c|c|c|c|c|c|c|c|c|c|c|c|c|c|c|c|c|c|c|}
\hline \multicolumn{9}{|c|}{ Evaluation 1} & \multirow[b]{2}{*}{$\begin{array}{c}\text { Available } \\
\text { control } \\
\text { measure } \\
\text { s }\end{array}$} & \multicolumn{4}{|c|}{ Evaluative 2} & \multirow[b]{2}{*}{$\begin{array}{l}\text { Propose } \\
\text { d } \\
\text { control } \\
\text { measur } \\
\text { es }\end{array}$} & \multicolumn{4}{|c|}{ Evaluative 3} \\
\hline 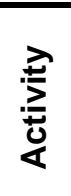 & $\frac{\ddot{\omega}}{\tilde{\alpha}}$ & 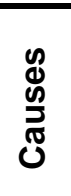 & 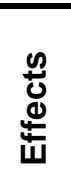 & 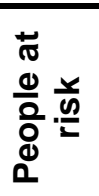 & 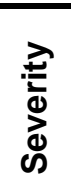 & 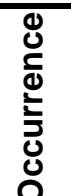 & 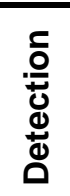 & $\frac{z}{\alpha}$ & & $\begin{array}{l}\frac{7}{\overline{0}} \\
\text { ले } \\
\text { ल }\end{array}$ & 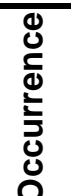 & 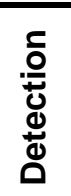 & $\frac{z}{\underline{z}}$ & & ڤ & 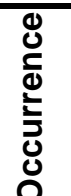 & 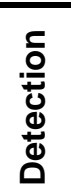 & $\frac{z}{\alpha}$ \\
\hline
\end{tabular}

To identify the risks, causes, and effects of the jobs, we first started analyzing job tasks using the HTA method. This method was introduced by Annett (1971) and developed by other researchers. In this method, the studied occupation was considered as the ultimate goal, and to achieve the goal, the task was divided into the details necessary for doing the activity. In the next step, the occurrence of human errors was determined using the mentioned technique (23).

Table 2: Severity Index (S)

\begin{tabular}{cl}
\hline Scores & \multicolumn{1}{c}{ Description of injuries or damage } \\
\hline $\mathbf{9 - 1 0}$ & Death or loss of a body function; regretfully \\
\hline $\mathbf{7 - 8}$ & Permanent reduction of a body function; dangerous \\
\hline $\mathbf{4 - 6}$ & Medium injuries and damage; most users are harassed. \\
\hline $\mathbf{3}$ & Temporary injuries and damage; severe deterioration \\
\hline $\mathbf{2}$ & A temporary injury or damage that requires intervention and treatment; low deterioration \\
\hline $\mathbf{1}$ & No injury and damage (only requires monitoring the patient); quite low deterioration \\
\hline
\end{tabular}

The severity of the risk is the result of the failure state. The probability of the occurrence is associated with the chance or probability of the failure state. It is also unlikely to detect the failure state due to the difficulty in identifying it (21). Calculation results for each factor have been shown in the following tables. The risks are rated according to the factors of severity, occurrence, and detection.

The factor of severity of the risks is obtained using Table 2.

Table 4: Detection Index (D)

\begin{tabular}{cl}
\hline Scores & Detection rate \\
\hline $\mathbf{9 - 1 0}$ & Very low \\
\hline $\mathbf{7 - 8}$ & Low (2 out of every 10 cases) \\
\hline $\mathbf{4 - 6}$ & Medium (5 out of every 10 cases) \\
\hline $\mathbf{3}$ & High (detected during the process)-(6-7 out of every 10 cases) \\
\hline $\mathbf{2}$ & Very high (found when occurring according to the process)-(8 out of every 10 cases) \\
\hline $\mathbf{1}$ & Occurrence failure is prevented by a coded instruction (9 out of every 10 cases)
\end{tabular}

The higher RPNs need to be prioritized for a more comprehensive analysis and resource allocation. At this stage, the team suggests actions reducing the RPN. The RPN is calculated based on the
In addition, the probability of the occurrence factor is obtained using Table 3 .

Table 3:Occurrence Index (O)

\begin{tabular}{cl}
\hline Scores & \multicolumn{1}{c}{ Likelihood of risk } \\
\hline $9-10$ & Too high- occurs normally \\
\hline $7-8$ & High- repeatable \\
\hline 4- 6 & Medium \\
\hline $2-3$ & Low \\
\hline 1 & Very low \\
\hline
\end{tabular}

The detection rate is obtained using Table 4 
Equation $1 \quad \mathrm{RPN}=\mathrm{S} \times \mathrm{O} \times \mathrm{D}$

$\mathrm{S}=$ Severity

$\mathrm{O}=$ Occurrence

$\mathrm{D}=$ Detection

Color and contour maps are the same as conventional graphical methods for the expression and assessment of work environments. These maps are utilized to identify various areas of the site based on the safety defined. To draw the maps, the site was first divided into chess areas of equal dimensions $(5 \times 5 \mathrm{~m} 2)$. The center of each area was considered as the measurement station. After carrying out the measurements, the results were entered into the plant station and then into the file format (input data) into ArcGIS 10.2. In the next step, according to the three common areas already mentioned, the safety contour maps were drawn. In these maps, isolinesare aligned to each other. These lines, like topographic maps, show safety ranges (22). The risk of each project is different and depends on the management policies as well as theseverity of the failure; hence, we would have:

The safety area is of a (Low Risk) with RPN $\leq 35$ (in green), and the caution area is of a (Medium Risk) with $35<\mathrm{RPN} \leq 70$ (in yellow). The danger area is also of a (High Risk) with RPN $>70$ (in red). The results of this task were a colored and isoline map of the site. Next, the areas of safety, caution, and danger were identified. The most important area for controlling actions is related to the danger area.The fulfillment of the code of ethics for this study was approved by the Ethics Committee of Kerman University of Medical Sciences (IR.KMU.REC.1397.302). In addition, a written informed consent from was obtained from all participants. The mean, standard deviation, and percentage of information were also computed using SPSS Statistics V22.0. Furthermore, the safety contour maps were drawn using ArcGIS V10.2.

\section{Results}

Table 5 presents results from the statistical analysis of demographic data. The highest average age is 39 for the management, and the lowest average age is 26 for the health and safety unit. The highest work experience is for the asphalting unit with an average of 18 years, and the minimum work experience is for flaggers and the Health and Safety Department with an average of one year.

Table 5: Demographic information of the individuals

\begin{tabular}{|c|c|c|c|c|c|}
\hline Unit Name & Demographic Data & Mean $\left( \pm \mathrm{SD}^{\star}\right)$ & Unit Name & Demographic Data & Mean $\left( \pm \mathrm{SD}^{\star}\right)$ \\
\hline \multirow{2}{*}{ Controller } & Age & $30( \pm 4)$ & \multirow{2}{*}{ Light machinery } & Age & $35( \pm 6)$ \\
\hline & Job experience & $5( \pm 1)$ & & Job experience & $8( \pm 3)$ \\
\hline \multirow{2}{*}{ Loader } & Age & $38( \pm 5)$ & \multirow{2}{*}{ Supporter } & Age & $35( \pm 5)$ \\
\hline & Job experience & $10( \pm 2)$ & & Job experience & $7( \pm 3)$ \\
\hline \multirow[b]{2}{*}{ Grader } & Age & $37( \pm 5)$ & \multirow{2}{*}{$\begin{array}{c}\text { Dump and Water } \\
\text { Tankers }\end{array}$} & Age & $36( \pm 6)$ \\
\hline & job experience & $13( \pm 3)$ & & Job experience & $15( \pm 5)$ \\
\hline \multirow{2}{*}{ Asphalt Factory } & Age & $37( \pm 6)$ & \multirow{2}{*}{ Dirt Rollers } & Age & $36( \pm 4)$ \\
\hline & Job experience & $8( \pm 2)$ & & Job experience & $15( \pm 3)$ \\
\hline \multirow{2}{*}{$\begin{array}{l}\text { Water Supply } \\
\text { Plant }\end{array}$} & Age & $30( \pm 2)$ & \multirow{2}{*}{ Repairs } & Age & $35( \pm 4)$ \\
\hline & Job experience & $2( \pm 0.5)$ & & Job experience & $10( \pm 4)$ \\
\hline \multirow{2}{*}{ Kitchen } & Age & $28( \pm 2)$ & \multirow{2}{*}{ Flagger } & Age & $25(-)$ \\
\hline & Job experience & $4( \pm 1)$ & & Job experience & $1(-)$ \\
\hline \multirow{2}{*}{ Installations } & Age & $27( \pm 2)$ & \multirow{2}{*}{ Finisher } & Age & $38(-)$ \\
\hline & Job experience & $3( \pm 1)$ & & Job experience & $12(-)$ \\
\hline \multirow{2}{*}{ Security-Guard } & Age & $35( \pm 4)$ & \multirow{2}{*}{ Asphalt Rollers } & Age & $38( \pm 5)$ \\
\hline & Job experience & $6( \pm 2)$ & & Job experience & $15( \pm 4)$ \\
\hline \multirow{2}{*}{$\begin{array}{l}\text { Welding- } \\
\text { Cutting }\end{array}$} & Age & $38( \pm 3)$ & \multirow{2}{*}{$\begin{array}{l}\text { Administrative and } \\
\text { Financial Affairs }\end{array}$} & Age & $35( \pm 4)$ \\
\hline & Job experience & $3( \pm 1)$ & & Job experience & $8( \pm 3)$ \\
\hline \multirow{2}{*}{ Management } & Age & $39( \pm 4)$ & \multirow{2}{*}{ Safety- Health } & Age & $24(-)$ \\
\hline & Job experience & $10( \pm 2)$ & & Job experience & $1(-)$ \\
\hline \multirow{2}{*}{$\begin{array}{l}\text { Technical } \\
\text { Office }\end{array}$} & Age & $30( \pm 5)$ & \multirow{2}{*}{ Crusher } & Age & $35( \pm 3)$ \\
\hline & Job experience & $5( \pm 2)$ & & Job experience & $8( \pm 1)$ \\
\hline \multirow{2}{*}{ Performance } & Age & $28( \pm 3)$ & \multirow{2}{*}{ Asphalt } & Age & $38( \pm 4)$ \\
\hline & Job experience & $4( \pm 2)$ & & Job experience & $18( \pm 4)$ \\
\hline \multirow{2}{*}{ Surveyor } & Age & $28( \pm 3)$ & \multirow{2}{*}{ Lab } & Age & $35( \pm 3)$ \\
\hline & Job experience & $4( \pm 1)$ & & Job experience & $8( \pm 1)$ \\
\hline \multirow{2}{*}{ Store } & Age & $26( \pm 2)$ & & & \\
\hline & Job experience & $2(-)$ & & & \\
\hline
\end{tabular}


The average RPN for each unit is presented in Table 6. As demonstrated, the highest and lowest
RPNs have been obtained for the light machinery and the laboratory unit, respectively.

Table 6: Safety of the units according to RPNs

\begin{tabular}{lccccc}
\hline \multicolumn{1}{c}{ Unit name } & $\begin{array}{c}\text { Average RPN } \\
\text { score }\end{array}$ & Unit name & $\begin{array}{c}\text { Average RPN } \\
\text { score }\end{array}$ & Unit name & $\begin{array}{c}\text { Average RPN } \\
\text { score }\end{array}$ \\
\hline Controller & 39.5 & Technical office & 30.6 & Finisher & 40.75 \\
\hline Loader & 32.67 & Performance & 37.25 & Asphalt rollers & 41.3 \\
\hline Grader & 40.27 & Surveyor & 38.17 & $\begin{array}{c}\text { Administrative } \\
\text { and financial } \\
\text { affairs }\end{array}$ & 31.25 \\
\hline Asphalt factory & 38.56 & Store & 30.44 & Safety- health & 35.03 \\
\hline $\begin{array}{l}\text { Water supply } \\
\text { plant }\end{array}$ & 25.93 & Light machinery & 42.91 & Crusher & 37.7 \\
\hline Kitchen & 30.06 & Supporter & 32.86 & Asphalt & 41.23 \\
\hline $\begin{array}{l}\text { Installations } \\
\text { Security-guard }\end{array}$ & 35.72 & $\begin{array}{c}\text { Compressor } \\
\text { and water } \\
\text { tanker }\end{array}$ & 35.75 & Flagger & 40.55 \\
\hline Welding- cutting & 29.56 & Dirt rollers & 40.27 & Laboratory & 0 \\
\hline
\end{tabular}

The percentages of risk severity for the site units are shown in Figure 1. As demonstrated, 62.97\% of the units are of medium risks, and the rest $(37.03 \%)$ are of low risks.

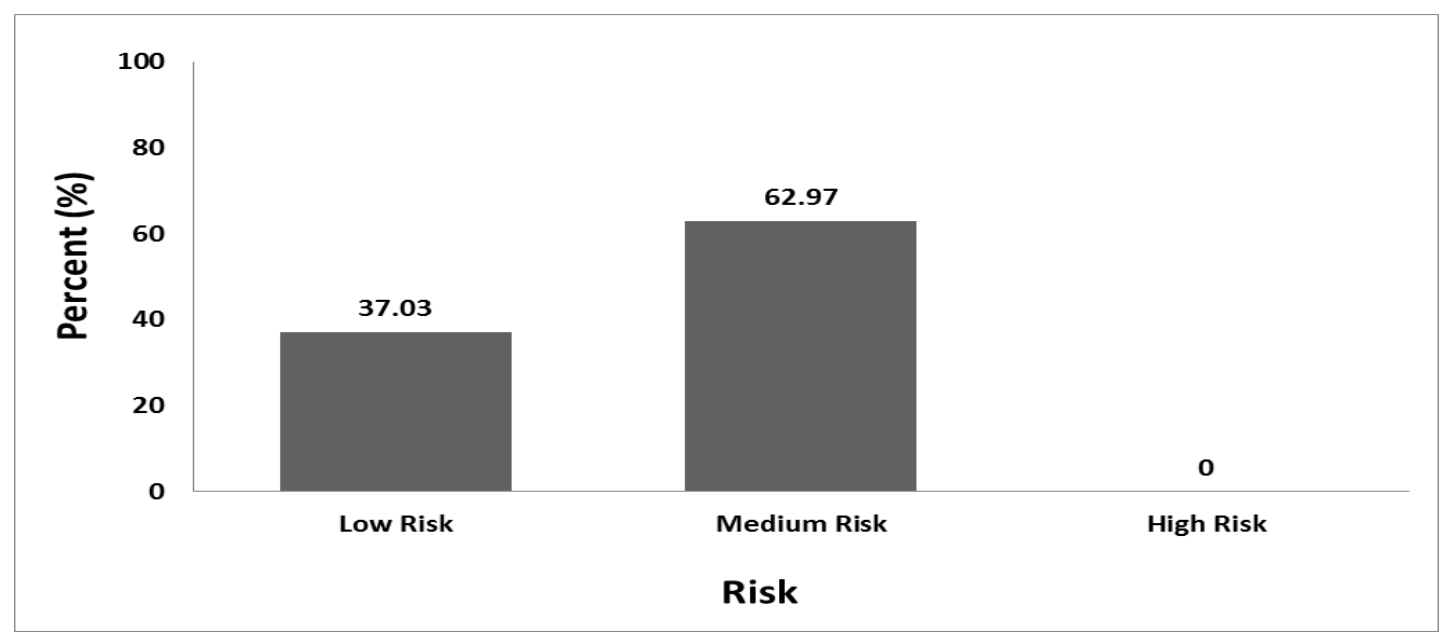

Figure 1: Percentages of risk severity for the site units

Figure 2 shows safety and caution areas on the color map of the site. As one can see, although the number of safe units is low, most of the points on the map are green and only few of them are yellow, because the software considers the space between the units to be safe as well.

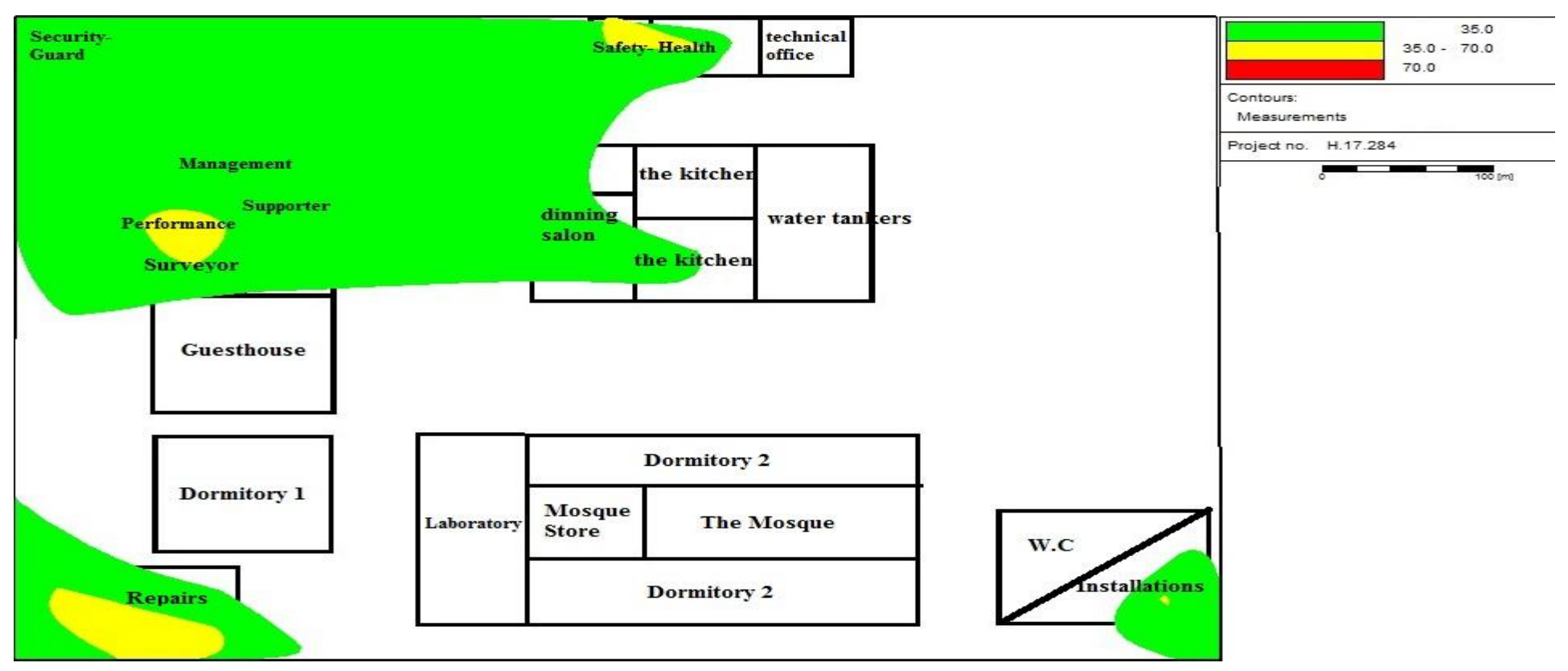

Figure 2: Safety Contour Map of the site 


\section{Discussion}

The units with the highest average RPN value were light machineries valued 42.91, asphalt rollers valued 41.3, asphalting valued 41.23, finishers valued 40.75 , flaggers valued 40.55 , as well as graders and dirt rollers valued 40.27 each. The units with the lowest average RPN were laboratory units valued 0 , the water supply plant valued 25.93, safety guards valued 29.56, the kitchen valued 30.06 , and finally the store unit valued 30.44 (Table 5). In addition, $37.03 \%$ of the units had low risks, and $62.97 \%$ of them had moderate risks. There were also no high-risk unit at the site (Fig. 1).

In the case study of Lotfolahzadeh et al (2017) titled "Risk Assessment and Determination of Insurance Rate by the FMEA Method- a Case Study in a Cement Factory" conducted in a cement factory in Tehran, the risk level of the project included low $=\mathrm{RPN}<100$, medium $=100<\mathrm{RPN}<$ 126 , and high $=R P N>126$. Major activities with the RPN of over 126 were 68 risks, 51 risks were moderate with the RPN between 100 to 126, and 63 risks were lower than $\mathrm{RPN}=100$ (24). In the present study, units with an RPN of over 70 were considered to be of high risks, units with an RPN between 35 and 70 were considered to be of moderate risks, and those with an RPN lower than 35 were considered to be of low risks. Likewise, lightweight machines, asphalt rollers, as well as asphalt cutters and finishers were considered to be of high risks. In a study by Ghaljahi et al (2017) titled "Identification and Assessment of Risks in a Flour Factory using Failure Modes and Effects Analysis and Job Safety Analysis in the Golestan Province", the risk level of the project was determined to be low $=\mathrm{RPN}<85$, medium $=$ $85<\mathrm{RPN}<95$, and high $=\mathrm{RPN}>96$. In this regard, $45.54 \%, 36.36 \%, 9.09 \%$, and $0.09 \%$ of the identified risks were within the unacceptable, unfavorable, acceptable, and inconsiderable risk levels, respectively. In addition, the risk assessment of the factory environment and the flour grinder machine (Waltz) through the FMEA revealed the risk level of less than 85 , which was within the acceptable limit (25). In the present study, the greatest number of the risks was related to light machineries. In addition, units with an RPN of over 70 were of high risks, those with an RPN of between 35 and 70 were considered to be of moderate risks, and the ones with an RPN of lower than 35 were regarded to be of low risks. In addition, most of the units $(62.97 \%)$ had medium risks, and $37.03 \%$ of them had low risks.

Sadat Hosseini et al (2012) conducted a study titled "Occupational Health \& Safety Management in the Oil Rack Construction Phase and Providing Improvement Management Solutions in the Rashadat Oil Field Construction". The risks with an RPN of 1 to 90 were considered low, the risks with an RPN of 91 to 200 were considered medium, and those with an RPN of over 200 were considered high. In this study, $62.7 \%$ of the activities were of low risks, $31.6 \%$ of them had moderate risks, and the rest had the high risk of $5.7 \%(26)$. In the current study, most of the units $(62.97 \%)$ had medium risks, and $37.03 \%$ of them had low risks. In addition, units with an RPN of over 70 were considered to be of high risks, those with an RPN of between 35 and 70 were considered to be of moderate risks, and units with an RPN of 35 were considered to be of low risks. In 2012, Ebrahimzadeh et al studied the milling, welding, transport, and moving of the objects in Shiraz refinery. In a study titled "Assessing the Potential Dangers of Shiraz Refinery by FMEA and its Consequences", RPNs with a value of 48 were considered to be of low risks for welding, and activities such as scraping metal surfaces and cylinders with an RPN of 210 were considered to be of high risks. They also concluded that activities with lower RPNswere more damaging (27). In the present study, units with an RPN of over 70 were considered to be of high risks, those with an RPN between 35 and 70 were considered to be of moderate risks, and those with an RPN of less than 35 were considered to be of low risks. The activities of lightweight machineries with an RPN of 42.19 and asphalt rollers with an RPN of 41.3 were considered to be of high risks, and the activities of the laboratory and the water supply plant with an RPN between 0 and 25.93 were considered to be of low risks.

In a study titled "An Evaluation of FMEA Risk Factors at a School's Equipment Production Plant", Myrhammed et al investigated 12 workstations with 55 employees at a School's Equipment Manufacturing Plant. In 2016, having identified 51 risk factors in their study, they found out that $25.4 \%$ of the risk factors were within an acceptable range, $54.9 \%$ of them were within an unacceptable range, and $19.6 \%$ of them were under emergency conditions. The most demanding task was to work on guillotines (a kind of machine for cutting the things), as well as cutting, bending, and drilling machines (28). In the present study, $37.03 \%$ of the units had low risks, and $62.97 \%$ of them had moderate risks, yet there was no high-risk unit identified at the site. In 2016, a study was carried out in the Parsian Gas Refining Company, titled "the Application of the FMEA Model to Assessing the Environmental and Safety Hazards of Gas Condensate Storage Tanks" by Wazdani et al. 
They identified the dangers using the Delphi method and then evaluated and prioritized them by AHP and FMEA methods. According to their results, possible fire caused by terrorist and deliberate factors had the highest environmental risks with an RPN of 1.824 , and the inhalation of vapors had the highest safety risks with an RPN of 3.384, during repairs (29). In the current study, lightweight machines with an RPN of 42.19 and asphalt rollers with an RPN of 41.3 had the highest risks, respectively. In contrast, the activities of the laboratory and the water supply plant had the lowest risks with the RPNs of 0 and 25.93, respectively.

Different types of software have been used to draw color maps in various occupational health courses, among which one can mention the study of Shoja et al (2018) to demonstrate UV-A radiation using the Surfer V.13 in the workplace environment of a steel company. They showed that the highest levels of ultraviolet radiation were related to the welding unit $(0.32 \mathrm{mw} / \mathrm{cm} 2)$. The comparison of the values obtained from ultraviolet ray measurements with the standards showed that all measured values were within the standard range (30). In the present study, the number of safe units was low, and most points on the map were green, yet only few points were yellow because the software considered the space between the units safe. In another study conducted in a shoe factory by Zare et al, they evaluated the individual and environmental sound pressure levels and presented the results using the Surfer software. In addition, the results of measuring environmental sound pressure levels showed that $32.3 \%$ of the measurement stations was located in the danger zone with the sound pressure levels having been greater than $85 \mathrm{dBA}(31)$. In the present study, $37.03 \%$ of the units had low risks, $62.97 \%$ of them had moderate risks, but there was no high-risk unit identified at the site. Nevertheless, most of the points on the map are green, and only few of them are yellow because the software considers the space between the units to be safe as well.

One of the strengths of this research was the use of ArcGIS and the drawing of safety color and contour maps for the first time. The research limitations also include the timeliness of risk assessments and the lack of collaboration by some individuals.

\section{Conclusion}

In this study, using the FMEA methodology and after determining the scope of the risks, $37.03 \%$ of the units showed to have low risks, and $62.97 \%$ of them had moderate risks, but there was no high- risk unit identified at the site. Nevertheless, lightweight machines, asphalt rollers, asphalt cutters, and finishers were of the highest risks. It is expected that upon the application of corrective suggestions, the risk of units will be minimized and stay low.

\section{Acknowledgement}

This article is derived from a research project with code number 97000438 sponsored by the Student Research Committee of Kerman University of Medical Sciences. We hereby extend our gratitude to the Research Committee, as well as the authorities, and the directors of Kerman University of Medical Sciences for their cooperation and support. We also appreciate the management of the highway construction site and its dedicated staff for their collaboration and daylong efforts.

Conflict of interest: None declared.

\section{References}

1. Fontaneda I, Camino López MA, Gonzalez Alcántara OJ, Ritzel DO. Gender differences in lost work days due to occupational accidents. Saf Sci 2019; 114:23-9.

2. Pietilä $J$, Räsänen $T$, Reiman $A$, Ratilainen $H$, Helander E. Characteristics and determinants of recurrent occupational accidents. Saf Sci 2018; 108:269-77.

3. Sanmiquel L, Bascompta M, Rossell JM, Anticoi HF, Guash E. Analysis of occupational accidents in underground and surface mining in Spain using data-mining techniques. Int $\mathrm{J}$ Environ Res Public Health 2018; 15(3):462.

4. Sarkar S, Vinay S, Raj R, Maiti J, Mitra P. Application of optimized machine learning techniques for prediction of occupational accidents. Comput Oper Res 2019; 106:210-24.

5. Ghamari F, Mohammadfam I, Mohammadbeigi $A$, Ebrahimi $H$, Khodayari M. Determination of effective risk factors in incidence of occupational accidents in one of the large metal industries, Arak (2005-2007). Iran Occupational Health Journal 2013; 9(4):89-96.

6. Alli BO. Fundamental principles of occupational health and safety. 2nd ed. Geneva,Switzerland: International Labour Organization; 2008.

7. Komaki J, Barwick KD, Scott LR. A behavioral approach to occupational safety: pinpointing and reinforcing safe performance in a food manufacturing plant. J Appl Psychol 1978; 63(4):434-45.

8. Mohammadfam I, Fatemi F. Evaluation of the relationship between unsafe acts and occupational accidents in a vehicle manufacturing. Iran Occupational Health Journal 2008; 5(3 and 4):44-50.

9. Mehdad A, Rahimi R, Atashpour SH. Comparison of occupational stress and 
occupational accidents frequency among off shore and onshore oil industry employees. Journal of Social Psychology 2011; 6(19):53-63.

10. Isla Díaz R, Diaz Cabrera D. Safety climate and attitude as evaluation measures of organizational safety. Accid Anal Prev 1997; 29(5):643-50.

11. Nori I, Meftahi H, Jamshidi S. A survey of the effects of working conditions, job relations and attitude towards safety on job accidents and unsafe work behaviors. Journal of Industrial Management 2011; 6(15):53-67.

12. Ostadi Moghadam H, Yekta AA, Heravian Shandiz J, Fahoul MJ, Afsharnia M. Prevalence and etiology of occupational eye accidents in Mashad industrial's workshop. Journal of Rehabilitation 2004; 5(4):53-7.

13. Mortazavi B, Mahdavi S, Asilian H, Arghami S, Gholamnia R. Identification and assessment of human errors in SRP unit of control room of Tehran Oil Refinery using HEIST technique (2007). Journal of Kermanshah University of Medical Sciences 2008; 12(3):e79969.

14. Al-Abdallat EM, Oqailan AM, Al Ali R, Hudaib AA, Salameh GA. Occupational fatalities in Jordan. J Forensic Leg Med 2015; 29:25-9.

15. Anyim FC, Ufodiama NM, Ekwoaba JO. Effective Health and Safety Management Programme: A Lubricant for Improving Working Conditions and Performance. Nigerian Journal of Management Studies 2013; 11(1/2):105-21.

16. Nivolianitou Z. Risk analysis and risk management: a European insight. Law, Probab Risk 2002; 1(2):161-74.

17. Puente J, Pino R, Priore P, de la Fuente D. A decision support system for applying failure mode and effects analysis. International Journal of Quality \& Reliability Management 2002; 19(2):137-50.

18. Stamatis $\mathrm{DH}$. Failure mode and effect analysis: FMEA from theory to execution. 1st ed. Milwaukee, Wisconsin, United States: American Society for Quality (ASQ) Press; 2003.

19. Rhee SJ, Ishii K. Using cost based FMEA to enhance reliability and serviceability. Advanced Engineering Informatics 2003; 17(3-4):179-88.

20. Pickard K, Muller P, Bertsche B. Multiple failure mode and effects analysis-an approach to risk assessment of multiple failures with FMEA. Paper presented at: Annual Reliability and Maintainability Symposium; 2005 Jan 24-27; Alexandria, VA, USA, USA.

21. Xiao N, Huang H-Z, Li Y, He L, Jin T. Multiple failure modes analysis and weighted risk priority number evaluation in FMEA. Eng Fail Anal 2011; 18(4):1162-70.
22. Chang AY, Parrales ME, Jimenez J, Sobieszczyk ME, Hammer SM, Copenhaver DJ, et al. Combining Google Earth and GIS mapping technologies in a dengue surveillance system for developing countries. Int $\mathrm{J}$ Health Geogr 2009; 8(1):49.

23. Mohammadfam I, Movafagh M, Soltanian A, Salavati M, Bashirian S. Assessment of human errors in the intensive cardiac care unit nursing profession using the SPAR-H. Tibbi-i-Kar 2015; $7(1): 10-22$.

24. Lotfolahzadeh A, Miri Lavasani M, Dehghani A. Risk Assessment and Determination of Insurance Rate by FMEA Method-Case Study in a Cement Factory. Occupational and Environmental Health 2017; 2(4):311-22

25. Ghaljahi M, Namrudi Sh. Identification and assessment of hazard risks in a flour mill by the JSA and FMEA methodology. Journal of Health Research in Community 2017; 3(3):82-9

26. Hosseini H, Dana T, Arjmandi R, Shirianpour I. Safety and Occupational Health Risk Management in construction phase of oil field and presenting Management strategies improve (Case study construction phase of platform's Reheat oil field). Human \& Environment 2012; 10(22):39-67.

27. Ebrahimzadeh M, Halvani GH, Mortazavi M, Soltani R. Assessment of Potential Hazards by Failure Modes and Effect Analysis (FMEA) Method in Shiraz Oil Refinery. Tibbi-i-Kar 2011; 3(2):16-23.

28. Mirmohammadi T, Naseripouya Z, Hosseinalipour Z. Risk factors assessment in educational equipment manufacturers company using FMEA. Journal of Health Research in Community 2016; 2(2):9-18.

29. Vazdani S, Sabzghabaei GhR, Dashti S, Cheraghi $M$, Alizadeh $R$, Hemmati $A$. Application of FMEA model for environmental, safety and health risks assessment of gas condensates storage tanks of parsian gas refining company in 2016. Journal of Rafsanjan University of Medical Sciences 2018; 17(4):34558.

30. Shoja E, Ebrahimian H, Gharaee M, Mehri M, Elahi $\mathrm{H}$, Mollaei R. Assessment and Mapping of Ultraviolet Radiation (UV-A) in a Workplace Environment of a Steel Industry. Journal of North Khorasan University of Medical Sciences 2018; 9(3):330-5.

31. Zare S, Hasheminejad N, Elahi Shirvan H, Hasanvand D, Hemmatjo R, Ahmadi S. Assessing Individual and Environmental Sound Pressure Level and Sound Mapping in Iranian Safety Shoes Factory. Romanian Journal of Acoustics and Vibration 2018; 15(1):20-5. 